\title{
Rapid Consolidation of Nanostructured TiCu Compound by High Frequency Induction Heating and Its Mechanical Properties
}

\author{
In-Jin Shon ${ }^{1, *}$, Na-Ri Kim ${ }^{1}$, Song-Lee $\mathrm{Du}^{1}$, In-Yoong Ko ${ }^{1}$, Sung-Wook Cho ${ }^{2}$ and Wonbaek Kim ${ }^{2}$ \\ ${ }^{1}$ Division of Advanced Materials Engineering, The Research Center of Advanced Materials Development, \\ Chonbuk National University, Jeonbuk 561-756, Korea \\ ${ }^{2}$ Minerals and Materials Processing Division, Korea Institute of Geoscience, Mining and Materials Resources, Daejeon, Korea
}

Nanosized $\mathrm{TiCu}$ powders were synthesized by high energy ball milling of micron-sized $\mathrm{Ti}$ and $\mathrm{Cu}$ powders. Dense TiCu could be consolidated by high frequency induction sintering method within $1 \mathrm{~min}$ using both horizontally milled elemental powders of $\mathrm{Ti}+\mathrm{Cu}$ and mechanically synthesized powders of $\mathrm{TiCu}$. The consolidation was accomplished under the combined effect of induced current and applied mechanical pressure. The grain size, sintering behavior and hardness of $\mathrm{TiCu}$ sintered from both powders were examined. [doi:10.2320/matertrans.M2010251]

(Received July 26, 2010; Accepted August 23, 2010; Published October 14, 2010)

Keywords: intermetallics, mechanical alloying, nanostructured materials, sintering

\section{Introduction}

Intermetallic compounds continually draw attention of materials scientist because of a potentially very attractive set of physical, chemical and mechanical properties. Among the intermetallics, TiAl and TiNi compounds have been studied by many investigators. TiCu has received relatively little attention. Recently, we noticed that Ti-Cu alloy is considered for the substitution of conventional dental cast alloy $\mathrm{Ti}-\mathrm{Ag}$ which is more expensive. ${ }^{1)}$

Traditionally, intermetallic compounds have been produced by several processing routes such as powder metallurgy, mechanical alloying, various casting techniques and SHS (self-propagating high temperature synthesis). One of all these techniques, high energy ball milling and mechanical alloying of powder mixtures, were reported to be efficient techniques for the preparation of nano-crystalline metals and alloys, which is a combination of mechanical milling and chemical reactions. ${ }^{2)}$ The MA technique allows one to overcome problems such as large difference in melting points of the alloying components as well as unwanted segregation or evaporation that could occur during melting and casting.

Nanocrystalline materials have received much attention as advanced engineering materials with improved physical and mechanical properties. ${ }^{3,4)}$ In recent days, nanocrystalline powders have been developed by the thermochemical and thermomechanical process named as the spray conversion process (SCP), co-precipitation and high energy milling. ${ }^{5-7)}$ However, the grain size in sintered materials becomes much larger than that in pre-sintered powders due to a fast grain growth during conventional sintering process. Therefore, controlling grain growth during sintering is one of the keys to the commercial success of nanostructured materials. In this regard, the high frequency induction heated sintering method which can make dense materials within 2 min, has been shown to be effective in achieving this goal. ${ }^{8,9)}$

The purpose of this work was to evaluate the feasibility of producing dense nanocrystalline $\mathrm{TiCu}$ compound using

*Corresponding author, E-mail: ijshon@chonbuk.ac.kr induced current activated sintering method in short time. The method was applied to horizontal ball milled $\mathrm{Ti}+\mathrm{Cu}$ powder and high-energy ball milled $\mathrm{TiCu}$ powders. The results were assessed in major terms of mechanical properties of hardness and fracture toughness.

\section{Experimental Procedures}

Powders of $99.5 \% \mathrm{Ti}$ (-400 mesh, Sezong, Inc) and $99 \%$ pure $\mathrm{Cu}(-625$ mesh, Alfa, Inc) were used as starting materials. $\mathrm{Ti}$ and $\mathrm{Cu}$ powders were mixed by two methods. Firstly, the powders were milled in a high-energy ball mill, Pulverisette-5 planetary mill with $250 \mathrm{rpm}$ and for $10 \mathrm{~h}$. Tungsten carbide balls $(8.5 \mathrm{~mm}$ in diameter) were used in a sealed cylindrical stainless steel vial under argon atmosphere. The weight ratio of ball-to-powder was $30: 1$. Secondly, the powders were mixed in polyethylene bottles using zirconia balls with ethanol and were milled at a horizontal rotation velocity of $250 \mathrm{rpm}$ for $10 \mathrm{~h}$. After milling, the mixed powders were placed in a graphite die (outside diameter, $45 \mathrm{~mm}$; inside diameter, $20 \mathrm{~mm}$; height, $40 \mathrm{~mm}$ ) and then introduced into the high frequency induction heated combustion system made by Eltek in South Korea shown in Refs. 8, 9). The four major stages in the sintering are as follows. The system was evacuated (stage 1). And a uniaxial pressure of $80 \mathrm{MPa}$ was applied (stage 2). An induced current was then activated and maintained until densification was attained as indicated by a linear gauge measuring the shrinkage of the sample (stage 3 ). Temperature was measured by a pyrometer focused on the surface of the graphite die. At the end of the process, the sample was cooled to room temperature (stage 4).

Microstructural information was obtained from product samples which were polished and etched using a solution of $\mathrm{H}_{2} \mathrm{O}(92 \mathrm{vol} \%), \mathrm{HF}(3 \mathrm{vol} \%)$ and $\mathrm{HNO}_{3}(5 \mathrm{vol} \%)$ for $30 \mathrm{~s}$ at room temperature. Compositional and micro structural analyses of the products were made through X-ray diffraction (XRD) and scanning electron microscopy (SEM) with energy dispersive X-ray analysis (EDAX). Vickers hardness was measured by performing indentations at load of $30 \mathrm{~kg}$ and a dwell time of $15 \mathrm{~s}$ on the synthesized samples. 


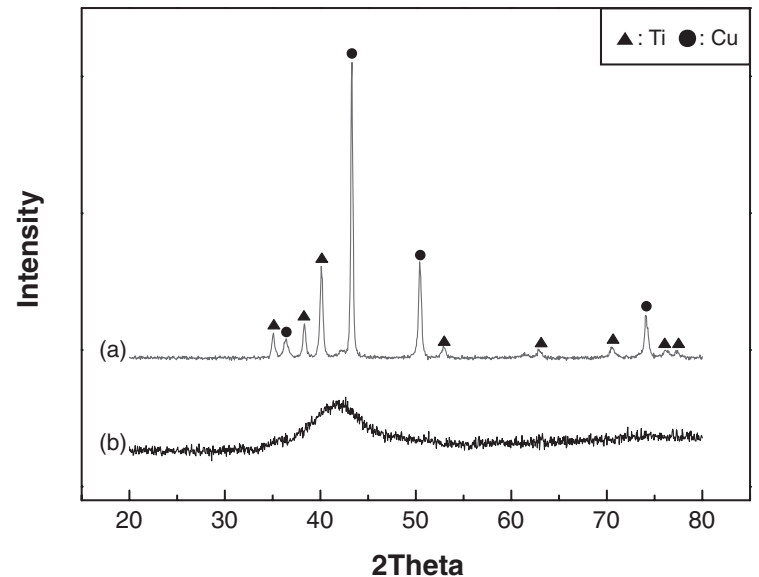

Fig. 1 XRD patterns of milled powder: (a) horizontal milled $\mathrm{Ti}$ and $\mathrm{Cu}$ powder, (b) high energy ball milled $\mathrm{TiCu}$ powder.
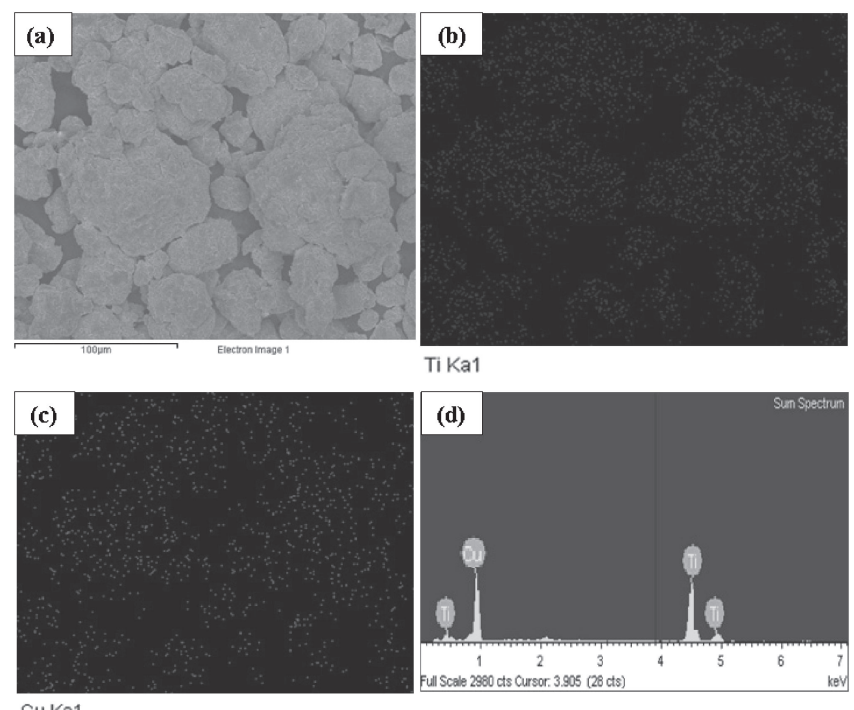

Fig. 2 FE-SEM image (a), X-ray mappig of Ti (b), Cu (c) and EDS (d) in high energy ball milled $\mathrm{TiCu}$ powder.

\section{Results and Discussion}

XRD patterns of milled powder are shown in Fig. 1. TiCu was not synthesized during the horizontal rotation ball milling in ethanol, But peak was broad during high-energy ball milling.

Figure 2 shows SEM image and X-ray mapping of highenergy ball milled powder. The powder is agglomerated with fine particles. And $\mathrm{Ti}$ and $\mathrm{Cu}$ are overlapped at the same position in X-ray mapping. Therefore, it is considered that $\mathrm{TiCu}$ compound was synthesized by high energy during high-energy ball milling. The synthesized $\mathrm{TiCu}$ and the $\mathrm{Ti}+\mathrm{Cu}$ powders were heated to $770^{\circ} \mathrm{C}$ with heating rate of $800^{\circ} \mathrm{C} / \mathrm{min}$ under $80 \mathrm{MPa}$ using high frequency induction heating.

Figure 3 shows X-ray diffraction patterns of sintered $\mathrm{TiCu}$. XRD showed peaks for $\mathrm{TiCu}$, as indicated in Fig. 3(a) and (b), along with those for a minor phase $\left(\mathrm{Cu}_{2} \mathrm{Ti}, \mathrm{Cu}_{4} \mathrm{Ti}_{3}\right.$, $\mathrm{Cu}_{3} \mathrm{Ti}$ ), as shown in Fig. 3. The presence of $\mathrm{Cu}_{2} \mathrm{Ti}, \mathrm{Cu}_{4} \mathrm{Ti}_{3}$, and $\mathrm{Cu}_{3} \mathrm{Ti}$ in the sample suggests a $\mathrm{Ti}$ deficiency. It is

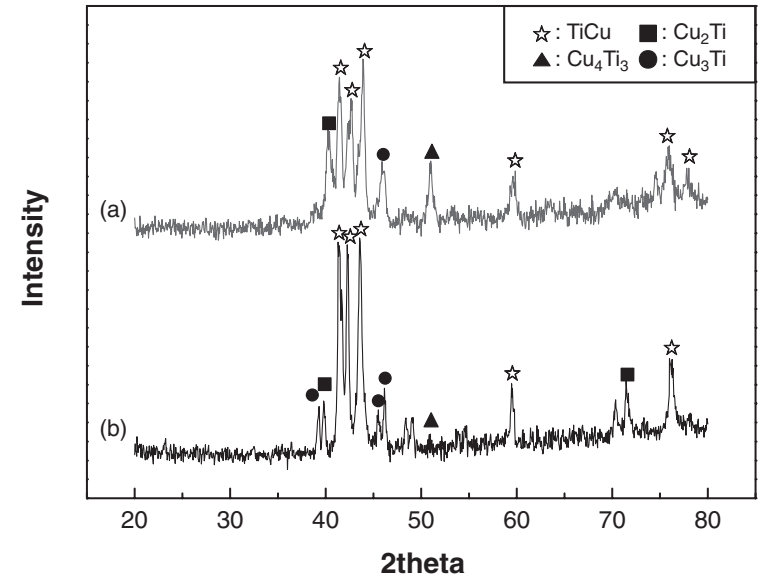

Fig. $3 \mathrm{XRD}$ patterns of $\mathrm{TiCu}$ sintered at $770^{\circ} \mathrm{C}$ : (a) horizontal milled $\mathrm{Ti}$ and $\mathrm{Cu}$ powder, (b) high energy ball milled $\mathrm{TiCu}$ powder.
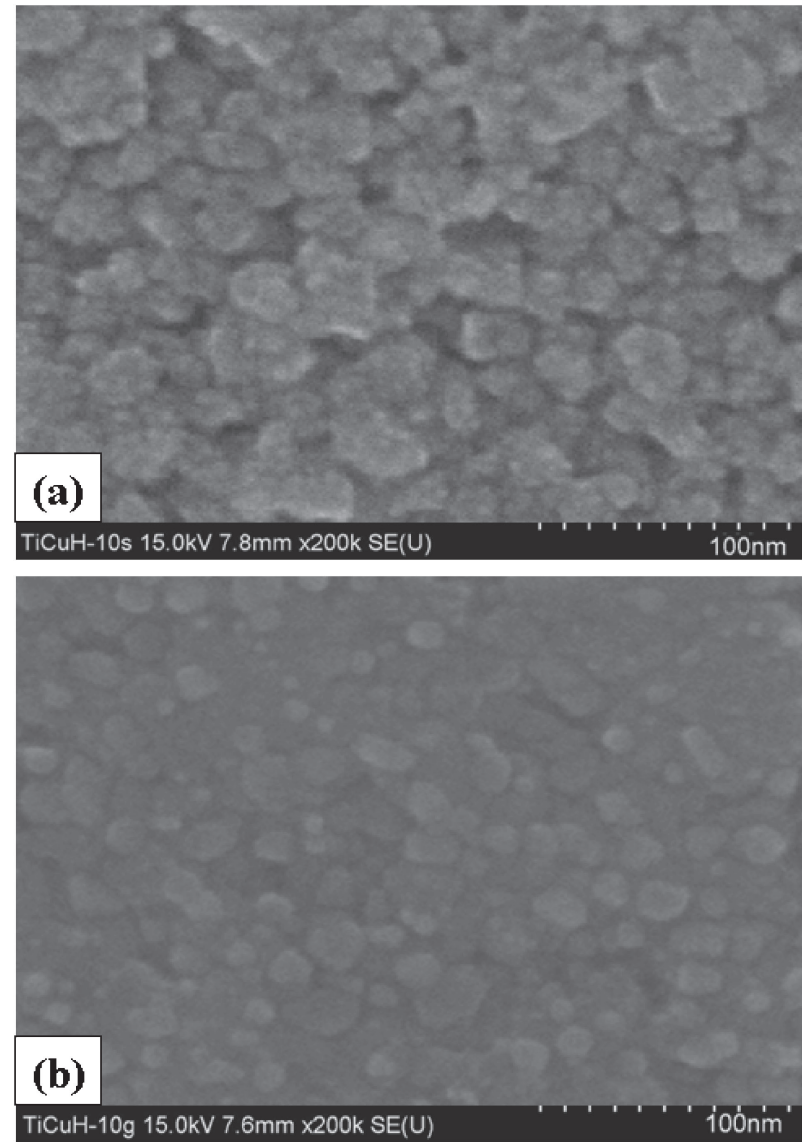

Fig. 4 FE-SEM images of $\mathrm{TiCu}$ sintered at $770^{\circ} \mathrm{C}$ : (a) horizontal milled Ti and $\mathrm{Cu}$ powder, (b) high energy ball milled $\mathrm{TiCu}$ powder.

believed that this observation is related to the entrapped oxygen in the pores of the interior portion of the sample during pressing or possibly to the slight oxidation of $\mathrm{Ti}$ during heating. When the reactant mixture of $\mathrm{Ti}$ and $\mathrm{Cu}$ was heated under $80 \mathrm{MPa}$ pressure to $770^{\circ} \mathrm{C}$, the starting powders $(\mathrm{Ti}+\mathrm{Cu})$ reacted producing products $(\mathrm{TiCu})$, shown in Fig. 3(a). Figure 4 shows FE-SEM images for TiCu sintered from (a) horizontally milled $\mathrm{Ti}+\mathrm{Cu}$ powders and (b) high energy ball milled $\mathrm{TiCu}$ powder. The structure parameters, 
i.e. the average grain size of (a) and (b) was about $40 \mathrm{~nm}$ and $20 \mathrm{~nm}$, respectively. And their poreless structure indicates that are sintered to near full density. This retention of the fine grain size during sintering is attributed to the high heating rate, the relatively short term exposure of the powders to the high temperature, the presence of plasma in pores separating powder particles, and the intrinsic contribution of the current to mass transport. ${ }^{10-13)}$

Vickers hardness measurements were made on polished sections of the TiCu using a $50 \mathrm{~kg}_{\mathrm{f}}$ load and $15 \mathrm{~s}$ dwell time. The calculated hardness value of the $\mathrm{TiCu}$ sintered from horizontal ball milled $\mathrm{Ti}+\mathrm{Cu}$ powder and high-energy ball milled TiCu powder were 570 and $710 \mathrm{~kg} / \mathrm{mm}^{2}$, respectively. This value represents an average of five measurements. Indentations with sufficiently large loads produced median cracks around the indent. The length of these cracks permits an estimation of the fracture toughness of the material by Niihara et al.'s expression: ${ }^{14)}$

$$
\mathrm{K}_{\mathrm{IC}}=0.023(c / a)^{-3 / 2} \cdot H_{\mathrm{v}} \cdot a^{1 / 2}
$$

where $c$ is the trace length of the crack measured from the center of the indentation, $a$ is half of the average length of two indent diagonals, and $H_{\mathrm{v}}$ is the hardness.

The calculated fracture toughness value of the $\mathrm{TiCu}$ sintered from horizontal ball milled $\mathrm{Ti}+\mathrm{Cu}$ powder and high-energy ball milled $\mathrm{TiCu}$ powder composite is about 5 and $7 \mathrm{MPa} \cdot \mathrm{m}^{1 / 2}$. As in the case of the hardness value, the toughness value is the average of five measurements. The mechanical properties (hardness and fracture toughness) of $\mathrm{TiCu}$ sintered from high energy ball milled $\mathrm{TiCu}$ is higher than those of $\mathrm{TiCu}$ sintered from horizontally milled $\mathrm{Ti}+\mathrm{Cu}$ powders due probably to grain refinement.

\section{Conclusions}

Using the high frequency induction heated sintering method, the densification of nanostructured $\mathrm{TiCu}$ was accomplished from mechanically synthesized powder of $\mathrm{TiCu}$ and horizontally milled $\mathrm{Ti}+\mathrm{Cu}$ powders. Near full density of $\mathrm{TiCu}$ could be obtained within duration of $1 \mathrm{~min}$ under the applied pressure of $80 \mathrm{MPa}$ and the induced current. The average grain sizes of $\mathrm{TiCu}$ prepared by high frequency induction heated sintering method from horizontally milled $\mathrm{Ti}+\mathrm{Cu}$ powders and high energy ball milled $\mathrm{TiCu}$ powder were about $40 \mathrm{~nm}$ and $20 \mathrm{~nm}$, respectively. The calculated hardness and fracture toughness values of $\mathrm{TiCu}$ sintered from horizontally milled $\mathrm{Ti}+\mathrm{Cu}$ powders and high energy ball milled TiCu powder were $570,710 \mathrm{~kg} / \mathrm{mm}^{2}$ and $5,7 \mathrm{MPa} \cdot \mathrm{m}^{1 / 2}$, respectively.

\section{Acknowledgment}

This study was supported by a grant from basic research project of Korea Institute of Geoscience and Mineral Resources.

\section{REFERENCES}

1) M. Takahashi, M. Kikuchi, Y. Takada and O. Okuno: Dental Mater. J. 21 (2002) 270-280.

2) S. Paris, E. Gaffet, F. Bernard and Z. A. Munir: Scr. Mater. 50 (2004) 691-696.

3) M. S. El-Eskandarany: J. Alloy. Compd. 305 (2000) 225-238.

4) L. Fu, L. H. Cao and Y. S. Fan: Scr. Mater. 44 (2001) 1061-1068.

5) Z. Fang and J. W. Eason: Int. J. Refractory Met. Hard Mater. 13 (1995) 297-303.

6) A. I. Y. Tok, L. H. Luo and F. Y. C. Boey: Matr. Sci. Eng. A 383 (2004) 229-234.

7) I. J. Shon, D. K. Kim, K. T. Lee and K. S. Nam: Metal. Mater. Int. 14 (2008) 593-598.

8) H. C. Kim, I. J. Shon, J. K. Yoon and J. M. Doh: Metal. Mater. Int. 12 (2006) 141-147.

9) H. C. Kim, I. J. Shon, I. K. Jeong and I. Y. Ko: Metal. Mater. Int. 12 (2006) 393-398

10) Z. Shen, M. Johnsson, Z. Zhao and M. Nygren: J. Am. Ceram. Soc. 85 (2002) 1921-27.

11) J. E. Garay, U. Anselmi-Tamburini, Z. A. Munir, S. C. Glade and P. Asoka-Kumar: Appl. Phys. Lett. 85 (2004) 573-575.

12) J. R. Friedman, J. E. Garay, U. Anselmi-Tamburini and Z. A. Munir: Intermetallics 12 (2004) 589-597.

13) J. E. Garay, U. Anselmi-Tamburini and Z. A. Munir: Acta. Mater. 51 (2003) 4487-95.

14) K. Niihara, R. Morena and D. P. H. Hasselman: J. Mater. Sci. Lett. 1 (1982) 12-16. 